DOI: https://doi.org/10.18309/anp.v51iesp.1522

\title{
CRÔNICAS COMO MEMORIAIS: A BRASÍLIA DE CLARICE LISPECTOR (E O TEMPORÁRIO DESAPARECIMENTO DO INVISÍVEL)
}

\author{
CHRONICLES AS MEMORIALS: THE BRASILIA OF CLARICE LISPECTOR \\ (AND THE TEMPORARY DISAPPEARANCE OF THE INVISIBLE)
}

\author{
Maria Caterina Pincherle \\ Sapienza Università di Roma, Roma, Italia \\ mariacaterina.pincherle@uniroma1.it \\ Tradução de Andréia Guerini \\ Universidade Federal de Santa Catarina, Florianópolis, Santa Catarina, Brasil \\ andreia.guerini@gmail.com
}

Resumo: Construída como uma alternância constante de investigações subjetivas e anotações subjetivas, a primeira crônica de Clarice Lispector sobre Brasília (publicada em Senhor, 1963) pode ser comparada a um memorial arquitetônico, que se encontra entre o estilo pessoal e a celebração pública, com um referente e uma intenção externa. Nas edições sucessivas (a partir do Jornal do Brasil, 1970) desaparece uma frase que menciona o estilo de "Estado totalitário" da cidade. A compreensível omissão da frase leva consigo também a sua apresentação como "manchete invisível nos jornais". Com a censura desaparece o 'invisível', como as estátuas inexistentes de Brasília celebradas por Clarice como conclusão de efeito.

Palavras-chave: Clarice Lispector; Brasília; Memorial

Abstract: Built upon alternating subjective and objective sentences, Clarice Lispector's first chronicle about Brasília (published on Senhor, 1963) is like an architectural memorial, half way between personal style and public celebration, with external reference and aim. In the following editions (from 1970 Jornal do Brasil on) a sentence is missing about the "Estado totalitário"like style of the city. Together with the omission of the sentence, its presentation as "invisible headline in the newspapers" is omitted. With censorship invisibility disappears, like the inexisting statues which Clarice celebrates as a catch-phrase.

Keywords: Clarice Lispector; Brasilia; Memorial 
O conteúdo deste meu texto poderia limitar-se ao título, esse por sua vez poderia agir como uma legenda aos textos de Clarice se republicados com um truque, do qual falarei.

A aproximação ao mundo da arquitetura deriva da ocasião pela qual inaugurei esta investigação. Chamada para falar de literatura brasileira em uma jornada dedicada aos Memoriais de Oscar Niemeyer, na Casa de Arquitetura de Roma, onde no início de 2018 foi organizada uma mostra fotográfica sobre esse tema, busquei falar das crônicas de Clarice Lispector sobre Brasília. Projetei a foto da primeira crônica de Clarice, tal como apareceu no Jornal do Brasil (JB) de 1970, depois de ter tido a sua estreia em Senhor em 1963: a forma do texto se apresentava com quatro colunas, sem espaços na paragrafação, pilares maciços com uma perfeição arquitetônica por si só acabada. De perto, observa-se como os parágrafos e a paragrafação foram substituídos pelos traços longos que intercalam as frases, de forma a criar ao mesmo tempo continuidade de leitura e de olhar(es), enquanto se prepara para a variedade do assunto.

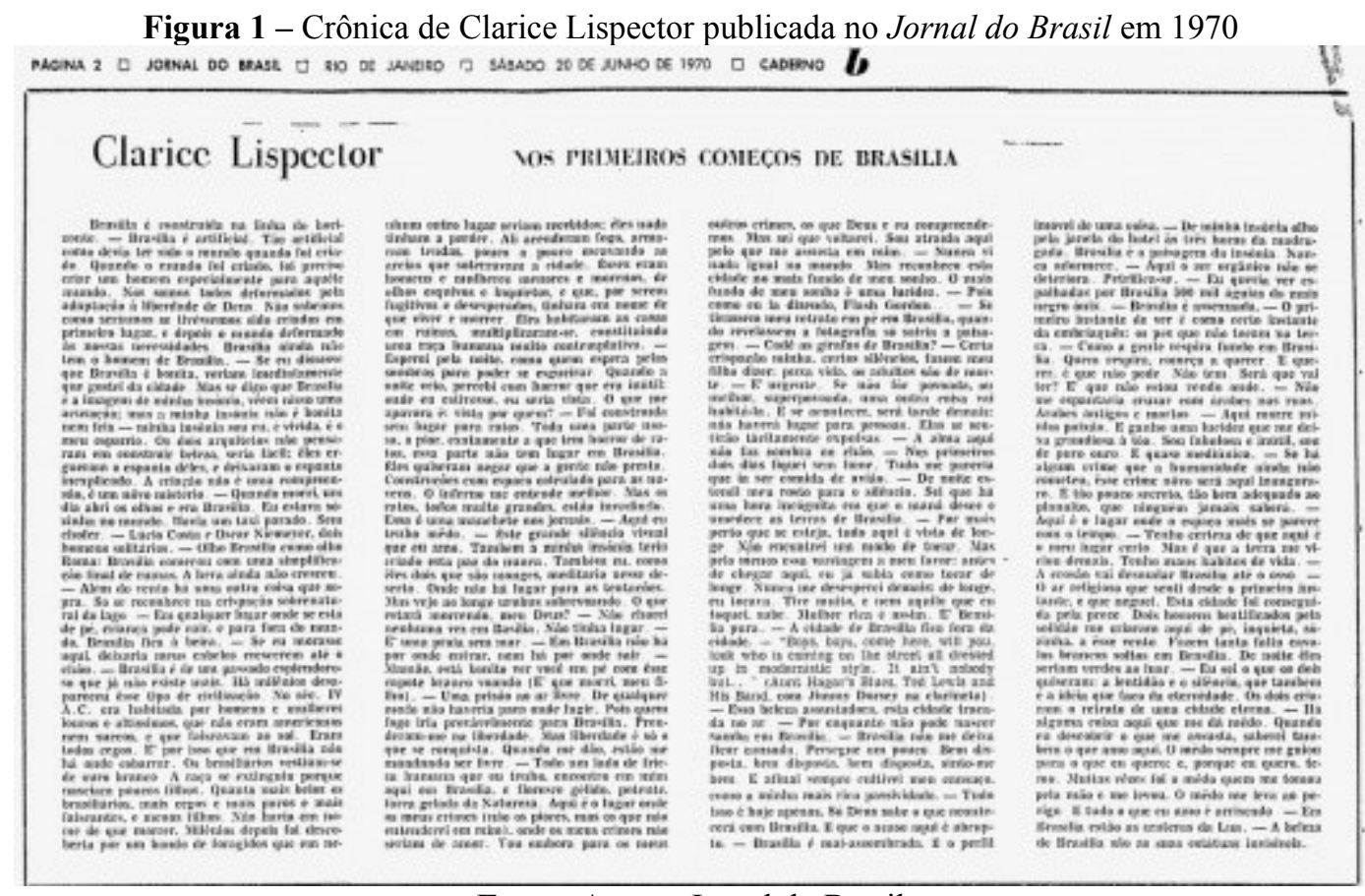

Fonte: Acervo Jornal do Brasil

A crônica, explicada para o público italiano, é um gênero ou subgênero, que funciona como um espaço literário intermediário entre o público e o privado, entre a história oficial e o comentário individual, no qual o escritor trata de um assunto de atualidade de maneira pessoal. É por esse motivo que no Brasil são escolhidos autores importantes para ocupar semanalmente as colunas dos principais jornais, desenvolvendo assim uma fidelização do público a um determinado jornal.

Acrescento que se o estudioso Philippe Lejeune (1975) individuava um pacto implícito de veracidade e introspecção entre o autobiógrafo que escreve e o leitor que lhe crê, é mesmo possível individuar na crônica um pacto diferente, baseado na personalização do material, no qual o leitor é chamado a apreciar do texto o lado individual, o aspecto peculiar e singular impresso na matéria narrada, que geralmente trata do mundo externo: leitor e autor sabem que não conta tanto o fato quanto o comentário e o modo original de desenvolvê-lo. 
Observo que a crônica em geral se presta perfeitamente a uma comparação com o memorial como forma de expressão: um objeto ligado a um referencial externo (ou a uma ocasião externa), que se coloca no meio do caminho entre o pessoal e o público, já que é destinado ao público, mas extremamente mais personalizado - no meio do caminho, isto é, entre engenharia (ou mesmo arquitetura) e escultura, entre ensaio e conto.

E isso é ainda mais claramente detectável nas crônicas sobre Brasília escritas por Clarice: especialmente na primeira é possível observar visivelmente destacando ou colorindo (e este é o truque técnico que antecipei) todas as frases de caráter subjetivo, que imediatamente ressaltarão em relação aos momentos subjetivos, fazendo emergir do textus a rede bem entrelaçada, na qual uma frase com uma referência pontual e com um recorte descritivo é embutida entre duas observações pessoais: e esse esquema que parece regular como um sistema, este trajeto entre um aspecto e outro é repetido em todo o desenvolvimento da crônica, em uma vertigem impressionante.

Em um intermezzo entre essa alternância se insere o surpreendente trecho, quase um apólogo, e quase ficção científica, sobre os "brasiliários", os habitantes originários e mitológicos da cidade, branquíssimos e com tendência crescente à cegueira e à esterilidade, suplantados por populações em fuga mais robustas e menos puras, forjadas pela luta pela sobrevivência e inclinadas à contemplação (judeus?). Sem solução de continuidade (além do tracinho usual), Clarice nos oferece, imediatamente depois, a sua experiência interior da noite na capital modernista. ${ }^{1}$

Se da crônica Clarice explora a característica personalização do objeto do discurso, de outra parte descarta a característica efêmera e marginal do jornal: o elemento quotidiano é eternizado, e o lema descritivo desse aspecto poderia ser aquele Para não esquecer que escolheu para uma coletânea póstuma em um volume de vários desses escritos. Eis, emersa, a função memorialística, análoga à do monumento: é dever recordar. Isso emerge das crônicas mais políticas que foram pesquisadas por outros, dentre os quais Yudith Rosenbaum (2010), Ettore Finazzi-Agrò (2013) e Luigia De Crescenzo (2016), em particular a partir daquele texto dedicado a "Mineirinho" que, com extraordinária potência expressiva, ecoava os golpes com os quais um menininho fora inutilmente massacrado pela polícia; golpes fatais infligidos à moral e à empatia entre os humanos.

As crônicas sobre Brasília são o lugar onde a mais cristalina abstração se conecta com o momento mais íntimo, uma declaração quase confessional sobre a sensação de ter encontrado o próprio espaço no mundo: "Aqui é o lugar onde o espaço mais se parece com o tempo. Tenho certeza de que aqui é o meu lugar certo" (LISPECTOR, 1970).

Quanto ao seu aspecto político, memorial, encontramos pelo menos uma pista incisiva, latejante, nas várias republicações das crônicas, uma pista que, como um rio cárstico, desaparece a um certo ponto para reaparecer mais adiante; em particular, desaparece em um dado momento histórico para reaparecer mais tarde. Vejamos.

Publicadas várias vezes, as crônicas sobre Brasília são principalmente duas (uma terceira é uma entrevista com dois arquitetos que moravam na capital, Paulo e Gisela Magalhães) ${ }^{2}$ : e são conhecidos como "Cinco dias" e "Esplendor". A primeira, publicada

\footnotetext{
${ }^{1}$ Ao contraponto entre as crônicas de Clarice e a construção de Brasília, nas intenções dos seus construtores e na sua efetiva realização, é dedicada a segunda parte do riquíssimo ensaio de Gilberto Figueiredo Martins, Estátuas invisíveis: experiência do espaço público na ficção de Clarice Lispector, São Paulo, Nankin/Edusp, 2010, pp. 122199.

2 "Brasília de ontem e de hoje", Jornal do Brasil, 7/10/1971, agora em A descoberta do mundo (1984), Rio de Janeiro, Rocco, 1999, pp. 426-428.
} 
originariamente como "Brasília" na seção "Children's Corner" na sofisticata revista Senhor, em fevereiro de 1963 (a sua visita à capital acontecera em 1962) ${ }^{3}$, é republicada no ano seguinte na segunda parte de A legião estrangeira (a seção "Fundo de gaveta") com o título "Cinco Dias" (Rio de Janeiro: Editora do Autor, 1964) para voltar a comparecer em 20 de junho de 1970 no Jornal do Brasil (é a versão das quatro colunas), desta vez intitulada "Nos primeiros começos de Brasília", e será incluída, junto com a segunda crônica, que é 1974, em Visão do esplendor de 1975 (e successivamente em Para não esquecer de 1978). Nessa última edição o primeiro texto se conclui com uma nota de explicação sobre a segunda visita à capital, que aconteceu doze anos depois, que introduz sucintamente o texto da relativa, longuíssima, segunda crônica ("Aí vai tudo o que eu vomitei").

Elemento frequentemente nomeado, sentimento recorrente, pelo menos na primeira crônica, é o "medo": ligação íntima com o mundo externo, visceral mais do que qualquer paixão, porque inconsciente e objetivável. "Quando morri, um dia abri os olhos e era Brasília. Eu estava sozinha no mundo. Havia um táxi parado. Sem chofer. Ai que medo" (LISPECTOR, $1970)^{4}$

E, mais adiante:

"Quando a noite veio percebi com horror que era inútil: onde eu estivesse eu seria vista. O que me apavora é: vista por quem?" (LISPECTOR, 1970).

Mas sobretudo, logo depois, sempre em uma alternância inextricável de frases do eu e frases dedicadas à espacialidade externa, encontramos uma declaração explosiva na sua icasticidade:

\begin{abstract}
Foi construída sem lugar para ratos. Toda uma parte nossa, a pior, exatamente a que tem horror de ratos, esta parte não tem lugar em Brasília. Eles quiseram negar que a gente não presta. Construção com espaço calculado para as nuvens. O inferno me entende melhor. Mas os ratos, todos muito grandes, estão invadindo. Essa é uma manchete invisível nos jornais. - Aqui eu tenho medo. - A construção de Brasília: a de um Estado totalitário. — Este grande silêncio visual que eu amo. (LISPECTOR, 1970).
\end{abstract}

Ratos enigmáticos, em uma cidade que os nega mas que eles começam a infestar. Frases enigmáticas - como tantas outras - que se relacionam com a já difícil situação política do país, antes da dramática virada. Emblematicamente a frase "A construção de Brasília: a de um Estado totalitário" desaparece na edição do $J B$ de 1970, tornando-se - para quem tivesse lido anteriormente a versão originária - um verdadeiro e próprio ato de "invisibilidade", uma manchete que desapareceu. A capital federal se tornou capital de um estado ditatorial. Mais ainda que um explícito chamado ao regime, o desaparecimento dessas frases marca uma ferida, uma verdade que não é mais possível dizer. O trecho no $J B$ diz: "Essa é uma manchete nos jornais. - Aqui eu tenho medo. - Este grande silêncio visual que eu amo".

\footnotetext{
${ }^{3}$ Agradeço Matias Molina, autor dos volumes A história dos jornais no Brasil, Companhia das Letras, que me enviou a fotografia das páginas de Clarice em Senhor.

${ }^{4}$ E ainda, em um entrelaçamento de atração e medo: "Sou atraída aqui pelo que me assusta em mim" (p. 42), "há alguma coisa aqui que me dá medo. Quando eu descobrir o que me assusta, saberei também o que eu amo aqui. $\mathrm{O}$ medo sempre me guiou para o que eu quero. E porque eu quero, temo (...) (p. 44)". Cito aqui a partir da edição Para não esquecer, São Paulo, Ática, 1979, pp. 40-44. E, significativamente, a segunda crônica sobre Brasília termina com um "Estou assustadíssima" (ibidem, pp. 44-63, p. 63).
} 
Fez-se desaparecer, junto com a referência à ditadura, a própria invisibilidade. Todo o resto continua regularmente na crônica. ${ }^{5}$ E nas edições sucessivas, como naquela em Para não esquecer, a frase na sua evidência reaparecerá. Mas em A Descoberta do mundo, outra coletânea póstuma de crônicas, que retira evidentemente o texto do $J B$, esta parte falta. ${ }^{6}$

Sempre balançando entre o medo íntimo e a limpidez objetiva da cidade, podemos concluir com uma última imagem deste memorial em pedra permanente que o tempo não conseguiu arranhar - um chamado à própria invisibilidade:

"O medo me leva ao perigo. E tudo o que eu amo é arriscado. - Em Brasília estão as crateras da Lua. - A beleza de Brasília são as suas estátuas invisíveis” (LISPECTOR, 1970).

\section{Referências}

DE CRESCENZO, L. "Diritto di punire" o "Potere di morte"? Crimine, violenza e giustizia in "Mineirinho" di Clarice Lispector, Altre modernità, n. 15, 2016, p.186-201.

FINAZZI-AGRÒ, E. A (im)possível resposta: Clarice Lispector e a obrigação ao testemunho. In: PIMENTEL, I. F.; REZOLA, M. I (orgs.). Democracia, ditadura. Memória e justiça política. Lisboa: Tinta da China, 2013, p. 433-445.

LEJUENE, Ph. Le pacte autobiographique. Paris: Seuil, 1975.

LISPECTOR, C. Nos primeiros começos de Brasília. Jornal do Brasil, Caderno B, Rio de Janeiro, 20 jun. 1970, p. 2. Disponível em

https://news.google.com/newspapers?nid=0qX8s2k1IRwC\&dat $=19700620 \& p r i n t s e c=$ frontpa ge\&hl=pt-BR. Acesso em: 01 out. 2020.

ROSENBAUEM, Y. A ética na literatura: leitura de "Mineirinho", de Clarice Lispector, Estudos Avançados, v. 24, n. 69, 2010, p. 169-182.

Recebido em: 16 de outubro de 2020 Aceito em: 10 de novembro de 2020

Publicado em Dezembro de 2020

\footnotetext{
${ }^{5}$ Curiosamente, porque sem necessidade aparente, na republicação do $J B$ da crônica desaparece também aquele " Ai que medo" depois da frase do táxi sem motorista. Para o resto, o texto é praticamente idêntico salvo retoques formais.

${ }^{6}$ A descoberta do mundo, op. cit, p. 292-295.
} 